\title{
Effect of Mixing Chamber Structure on a Steam Ejector Performance
}

\author{
H. J. Li ${ }^{1 *}$, S. Q. Shen ${ }^{2}$ \\ ${ }^{1}$ Electromechanics and Materials Engineering College, Dalian Maritime University, Dalian 116026, \\ China \\ ${ }^{2}$ Department of Power Engineering, Dalian University of Technology, Dalian 116024, China \\ Email: navy_li@163.com, zzbshen@dlut.edu.cn
}

\begin{abstract}
Ejector is a widely used fluid machine. It is usually used to increase vapor or liquid pressure or to make vacuum. Because the power for transportation of suction fluid is directly from motive fluid thermal energy through thermodynamic conversion process, it can make use of low grade energy, such as solar energy, waste heat[1].

As shown in Figure, it generally includes four parts: nozzle, absorber, mixing chamber and diffuser. In order to enhance ejector performance, it is important to study rules of effect of ejector components structure. While at present, studies on this aspect are not enough. Considering CFD method is flexible to adjust ejector components dimensions and its cost is low, 2-D Navier-Stokes equations with Chen-Kim $\kappa-\varepsilon$ model was used to simulate the complex flow field of an ejector. Further more, steam real properties was used in calculation instead of using ideal gas hypothesis to consider condensation happening in the convergence-divergence nozzle for an ejector with steam as working fluid[2].
\end{abstract}

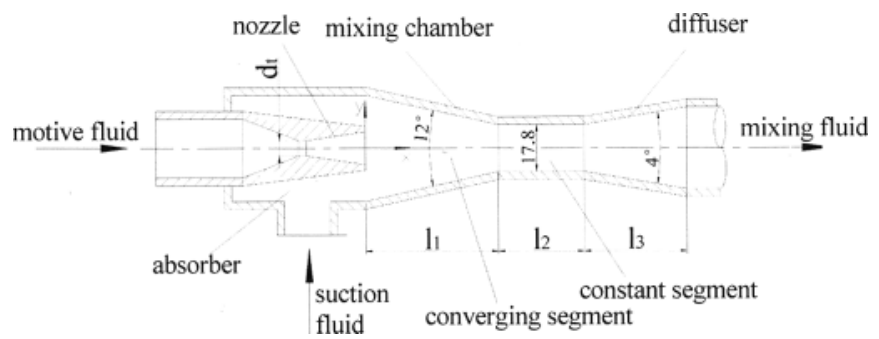

Figure: Schematic diagram of a steam ejector structure

Here effect of mixing chamber was studied. The more uniform mixing fluid is, the less energy loss through diffuser, so the higher discharging pressure will be obtained, which is important for ejector system using low grade energy as power. Through adjusting converging segment and constant segment of mixing chamber gradually, two kinds of mixing chamber structure were developed, one is for optimum entrainment ratio, and the other is for optimum critical discharging pressure. Two dimensionless parameters, expansion ratio and critical compression ratio, were used here instead of concrete parameter values to make the result universal.

\section{REFERENCES}

1. Selvaraju A, Mani A. Analysis of a vapor ejector refrigeration system with environment friendly refrigerants. International Journal of Thermal Sciences, 2004:43:915-921

2. Shen SQ, Li HJ, Simulation on phase change in supersonic flow in ejector. In: $4^{\text {th }}$ Int. Conference on Sustainable Energy Technologies, Jinan, China, 2005; 280-284 